\title{
Effect of Aluminum Addition to Nb-Al-C-N Coatings on AISI M2 Steel Obtained by Thermo-Reactive Deposition Technique
}

\author{
E. AbakaY*, S. Sen and U. Sen \\ Sakarya University, Engineering Faculty, Department of Metallurgy and Material Engineering, \\ 54187 Serdivan Sakarya, Turkey
}

\begin{abstract}
In this study, aluminum-doped (1 and $2 \mathrm{wt.} \%)$ and Al-free niobium carbo-nitride coatings were applied to the surface of AISI M2 high speed steel using the process of thermo-reactive deposition technique (TRD) at $1000{ }^{\circ} \mathrm{C}$ during 1-4 h. The obtained coatings were characterized by scanning electron microscopy (SEM), energy-dispersive X-ray spectroscopy (EDS), X-ray diffraction (XRD) analysis and micro hardness test. Nb-Al-C-N layers were compact and homogeneous. X-ray diffraction analysis has shown that the major phases formed in the coating layer are $\mathrm{Nb}_{2} \mathrm{CN}$ and $\mathrm{NbN}$. The depth of the coating layer had increased with the treatment time and ranged from 6.65 to $9.05 \mu \mathrm{m}$. The measured values of the hardness of the coating layers were ranging between 2136 and $2636 \mathrm{HK}_{0.005}$.
\end{abstract}

DOI: 10.12693/APhysPolA.129.653

PACS/topics: 81.40.Gh, 81.40.Ef, 62.20.Qp, 81.05.-t

\section{Introduction}

High-speed steel (HSS) materials have been widely used for extrusion, blanking, moulding and punching tools because of their mechanical properties, including high hardness, high wear resistance, excellent toughness and high temperature properties [1-2]. The lifetime of HSS, as tool materials, can be substantially improved through surface engineering methods, especially by the application of hard coatings like $\mathrm{TiN}, \mathrm{TiC}$ or $\mathrm{Ti}(\mathrm{C}, \mathrm{N})[3-$ 4]. Hard coatings can be prepared by different methods like physical vapor deposition (PVD), thermal spraying, and chemical vapor deposition (CVD) [5]. When compared with other techniques, TRD has several advantages such as requiring relatively simple equipment, low cost and being environmentally friendly [6]. During the TRD process, carbon and nitrogen in steel substrate diffuse into a deposited layer for formation of interstitial compounds with a carbide or nitride-forming elements, such as vanadium, niobium, tantalum, chromium, molybdenum or tungsten, which originate from the coating bath. The diffused carbon or nitrogen reacts with the carbide and nitride-forming elements in the deposited coating, so as to form a dense and metallurgically bonded carbide or nitride coating on the substrate surface [5]. Addition of aluminum to nitride-based hard coatings provides higher hardness, superior wear resistance, lower thermal expansion at high temperature, enhanced erosion resistance and chemical stability to harsh environments [7-9].

The aim of the present work is to investigate the effect of aluminum content on the microstructure, formation

*corresponding author; e-mail: eabakay@sakarya.edu.tr of phases and micro-hardness of the Nb-C-N coating produced by the TRD process onto the AISI M2 steel substrate.

\section{Experimental}

The substrates used in this study were made of AISI M2 high-speed-steel (HSS), produced by BohlerEdelstahl. The substrates were prepared with dimensions of $20 \mathrm{~mm}$ in diameter and $5 \mathrm{~mm}$ in thickness and were subsequently polished with 1200 grit emery paper and cleaned with acetone for ten minutes in an ultrasonic cleaner. The nitriding treatment of the substrates was realized by a low-pressure nitriding process at $530^{\circ} \mathrm{C}$ for $6 \mathrm{~h}$.

The coating process of pre-nitrided samples was performed by the TRD technique with a bath containing commercial ferro niobium, aluminium, ammonium chloride, alumina and naphthalene powders at $1000^{\circ} \mathrm{C}$ for 1 , 2 and $4 \mathrm{~h}$ in an electrical resistance furnace. Followed TRD treatment, coated samples subjected to quenching in the air. Aluminum was added to the coating bath in varying contents (Al-free, 1 and $2 \mathrm{wt.} \% \mathrm{Al}$ ).

For metallographic examination, the coated samples were ground using up to 1200 grit emery paper and polished using up to $0.3 \mu \mathrm{m}$ alumina paste and then etched with 3\% nital. Microstructural examinations and energy dispersive X-ray spectroscopy (EDS) analysis of the coatings were realized using JEOL JSM-6060 scanning electron microscopy (SEM). The phase analyses of the coated samples were carried out using X-ray diffraction (XRD) analysis using Rigaku XRD D/MAX/2200/PC $\mathrm{X}$-ray diffractometer with $\mathrm{Cu} \mathrm{K}_{\alpha}$ radiation. The hardness of the coating layers and substrates was measured using Future-Tech FM-700 micro-hardness tester. 


\section{Results and discussion}

Figure 1 shows the XRD patterns of the coatings realized for $4 \mathrm{~h}$ at $1000^{\circ} \mathrm{C}$. According to the patterns the phases in the samples are $\mathrm{Nb}_{2} \mathrm{CN}, \mathrm{NbN}, \mathrm{AlN}, \mathrm{Fe}_{3} \mathrm{~N}$ and $\mathrm{Mo}_{2} \mathrm{C}$. The coating baths have included ferro niobium, aluminum and ammonium chloride. Ammonium chloride decomposes at the coating temperature into $\mathrm{NH}_{3}$ and $\mathrm{HCl}$. Niobium and aluminum react with $\mathrm{HCl}$ and produce niobium chloride and aluminum chloride. Niobium and aluminum elements have relatively small free energies of carbide/nitride formation. The ratio of these phases depends on the bath content. In addition to these phases $\mathrm{Mo}_{2} \mathrm{C}$ and $\mathrm{Fe}_{3} \mathrm{~N}$ phases can be seen. These phases are found in nitrided AISI M2 structure [10-12].

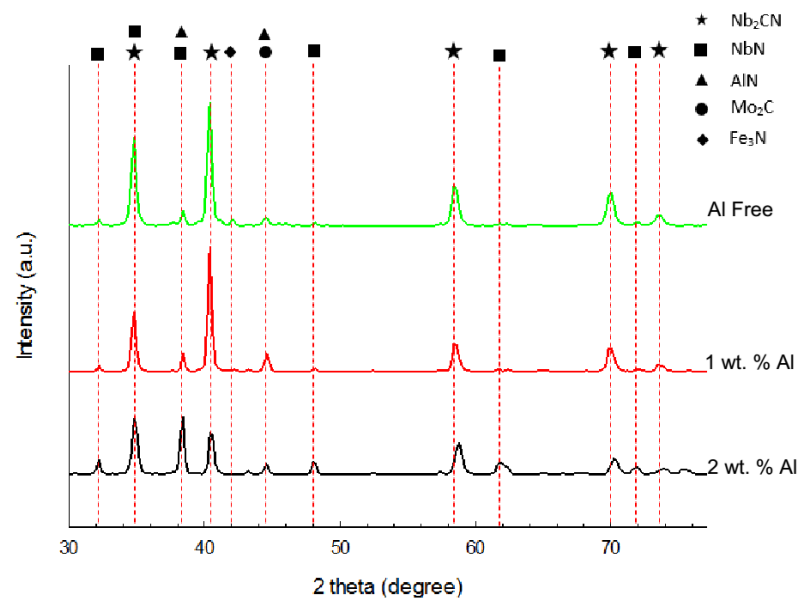

Fig. 1. XRD patterns of the Nb-Al-C-N coatings with various aluminum content, produced on AISI M2 steel at $1000^{\circ} \mathrm{C}$ for $4 \mathrm{~h}$.

Figure 2a shows SEM image of the cross-section of coated sample which included $1 \mathrm{wt} . \%$ of aluminum in coating bath, after processing time of $4 \mathrm{~h}$. According to Fig. 2a a dense, smooth and compact layer can be seen on the substrate. Additionally, three distinct regions can be distinguished in the image, which are: (i) the coating layer (ii) the transition zone between the layer and the substrate and (iii) the steel matrix. The EDS analyses of these regions are shown in Fig. 2b-d, respectively. As seen from the images, the coating layer has very high niobium concentration and any other elements cannot be seen, transition zone contains niobium with iron and there is no evidence of niobium diffusion into the steel substrate in Fig. 2d.

Hardness measurements have shown that the aluminum addition to the coating bath caused an increase of hardness. The hardness values of Al-free and 1 and 2 wt.\% Al dopped Nb-Al-C-N coating layers are $2136 \pm 96$, $2350 \pm 157$ and $2636 \pm 62 \mathrm{HK}_{0.005}$, respectively. According to Reiter et al., dissolution of aluminum within the $\mathrm{NbN}$ lattice induces strain in the coating layer, hindering the dislocation movement, which leads to the effect of increasing hardness [13].

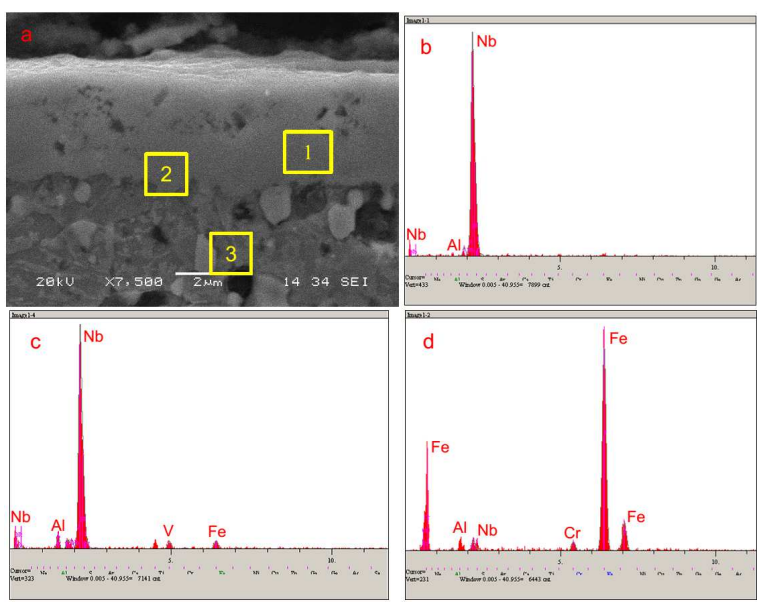

Fig. 2. SEM micrograph of a cross-section (a) and EDS analysis of the coating layer (b), the transition zone (c) and (d) substrate (d).

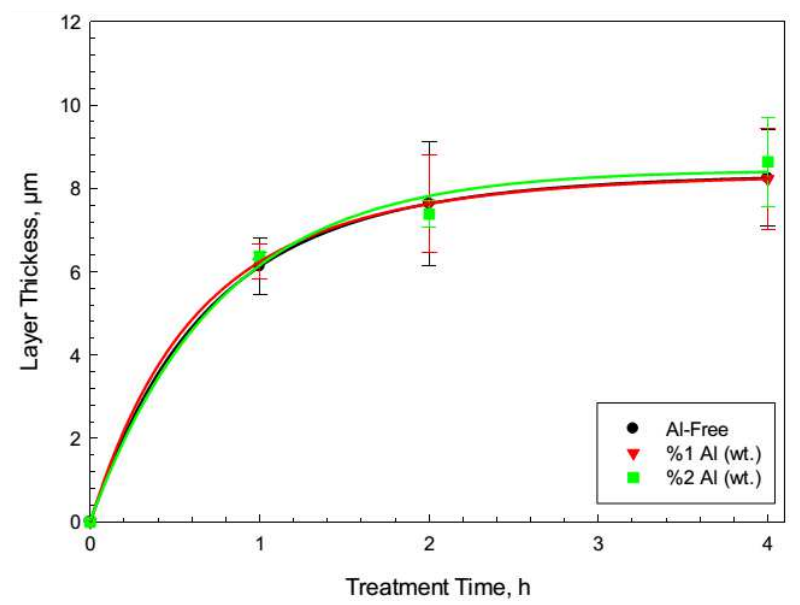

Fig. 3. The depth of the Nb-Al-C-N coating layer as a function of the treatment time for different $\mathrm{Al}$ contents in the coating bath.

The thickness of the layer had increased from 6.65 to $9.05 \mu \mathrm{m}$ with the increase of the treatment time, (see Fig. 3). In the thermo-chemical coating processes, increasing process time and the temperature causes an increase in the coating layer thickness. Bath composition, substrate, treatment time and temperature all affect the coating layer thickness in the thermo-reactive deposition processes [14]. In addition to this, $\mathrm{Al}$ content does not have any effect on the layer thickness.

\section{Conclusions}

In both cases regular layers were formed on AISI M2 steel, composed of niobium-based non-oxide phases. In addition to these phases, AlN was formed inside the coating layers after addition of aluminum to the coating bath. Microstructural examinations showed that a dense, smooth and metallurgically bonded layers were 
formed. Dissolution of aluminum in NbN lattices has induced strain in the coating layer, hindering the dislocation movement with the effect of increasing hardness from $2136 \pm 96$ to $2636 \pm 62 \mathrm{HK}_{0.005}$. Thickness of the layer was increasing with the increasing treatment time, however, the addition of aluminum to the bath had no effect on the layer thickness.

\section{References}

[1] L. Hao, Z. Jiang, D. Wei, Y. Zhao, J. Zhao, M. Luo, L. Ma, S. Luo, L. Jiang, Tribol. Int. 81, 19 (2015).

[2] I. Cho, A. Amanov, J. Kim, Tribol. Int. 81, 61 (2015).

[3] J. Narojczyk, Z. Werner, M. Barlak, D. Morozow, Vacuum 83, S228 (2009).

[4] J. Richter, Wear 257, 304 (2004).

[5] T. Arai, Thermochemical Surface Engineering of Steels, Woodhead Publishing, Oxford 2015, p. 703.
[6] X.S. Fan, Z.G. Yang, C. Zhang, Y.D. Zhang, H.Q. Che, Surf. Coat. Technol. 205, 641 (2010).

[7] D. Li, J. Chen, C. Zou, J. Ma, P. Li, Y. Li, J. Alloy. Compd. 609, 239 (2014).

[8] M. Hirai, Y. Ueno, T. Suzuki, W. Jiang, C. Grigoriu, K. Yatsui, Japan. J. Appl. Phys. 40, 1056 (2001).

[9] T. Weirather, K. Chladil, B. Sartory, D. Caliskanoglu, R. Cremer, W. Kölker, C. Mitterer, Surf. Coat. Technol. 257, 48 (2014).

[10] Hari-Bala, Y. Guo, X. Zhao, J. Zhao, W. Fu, X. Ding, Y. Jiang, K. Yu, X. Lv, Z. Wang, Mater. Lett. 60, 494 (2006).

[11] S. Sen, K. Kocaman, J. Mater. Sci. 46, 7784 (2011).

[12] C.K.N Oliviera, R.M.M. Riofano, L.C. Casteletti, Surf. Coat. Technol. 200, 5140 (2006).

[13] A.E. Reiter, V.H. Derflinger, B. Hanselmann, T. Bachmann, B. Sartory, Surf. Coat. Technol. 200, 2114 (2005).

[14] O. Ozdemir, S. Sen, U. Sen, Vacuum 81, 567 (2007). 